\title{
Desempenho agronômico das videiras 'Crimson Seedless' e 'Superior Seedless' no norte de Minas Gerais
}

\author{
Nelson Pires Feldberg ${ }^{(1)}$, Murillo de Albuquerque Regina ${ }^{(2)}$ e Mário Sérgio Carvalho Dias ${ }^{(3)}$
}

(1)Apta Regional, Pólo Regional Sudoeste Paulista, Rod. SP 250, Km 232, Caixa Postal 62, CEP 18300-000 Capão Bonito, SP. E-mail: npfeldberg@yahoo.com.br
(2)Núcleo Tecnológico Epamig Uva e Vinho, Av. Santa Cruz, 500, Caixa Postal 33, CEP 37780-000 Caldas, MG E-mail: murillo@epamigcaldas.gov.br
(3)Epamig, Centro Tecnológico do Norte de Minas, Rod. MGT 122, Km 155, Caixa Postal 12, CEP 39525-000 Nova Porteirinha, MG E-mail:mariodias@epamig.br

Resumo - O objetivo deste trabalho foi avaliar a influência do vigor dos porta-enxertos '1103 Paulsen' e 'IAC-572 Jales', no desempenho agronômico das cultivares Crimson Seedless e Superior Seedless. O experimento foi realizado na Fazenda Experimental da Epamig, em Mocambinho, distrito de Jaíba, MG, em delineamento inteiramente casualizado com sete repetições em esquema fatorial $2 \times 2$. Foram analisadas a fertilidade de gemas, o número e a massa de cachos e a massa de ramos. O porta-enxerto '1103 Paulsen' proporcionou os melhores resultados nas cultivares Crimson Seedless e Superior Seedless quanto à massa e número de cachos por planta e fertilidade de gemas, com produtividade média de 31,9 e 22,4 t ha- ${ }^{-1}$ ano $^{-1}$, respectivamente. O porta-enxerto 'IAC-572 Jales' proporcionou maior vigor, com maior massa de ramos por planta nas duas cultivares. O porta-enxerto '1103 Paulsen' induziu a maiores fertilidade de gemas e produtividades em 'Crimson Seedless' e 'Superior Seedless' e pode ser indicado para o cultivo na região de Jaíba, MG.

Termos para indexação: Vitis vinifera, porta-enxerto, uvas apirenas, vigor.

\section{Agronomic performance of 'Crimson Seedless' and 'Superior Seedless' vines in the north region of Minas Gerais}

\begin{abstract}
The objective of this work was to study the influence of the '1103 Paulsen' and 'IAC-572 Jales' rootstocks vigor in the agronomic performance of the cultivars 'Crimson Seedless' and 'Superior Seedless'. The experiment was carried in the Epamig Experimental Farm located in Mocambinho, Jaíba, MG, Brazil, in completely randomized experimental design with seven replications in factorial $2 \times 2$. The following variables were studied: bud fertility, number and weight of clusters and cane weight. The '1103 Paulsen' rootstock showed better results for cultivars 'Crimson Seedless' and 'Superior Seedless' regarding the number of clusters and their weight by plant and bud fertility, with average productivity of 31.9 and $22.4 \mathrm{t} \mathrm{ha}^{-1} \mathrm{year}^{-1}$, respectively. The 'IAC-572 Jales' rootstock provided higher vigor, comprising greater weight of canes per plant in both cultivars. The '1103 Paulsen' rootstock induced higher bud fertility and productivity for 'Crimson Seedless' and 'Superior Seedless' grapes and can be indicated for cultivation in the Jaíba region.
\end{abstract}

Index terms: Vitis vinifera, rootstock, seedless grapes, vigor.

\section{Introdução}

A produção de uvas finas para mesa está concentrada nas regiões sudoeste e noroeste de São Paulo, norte do Paraná, no Vale do São Francisco entre Pernambuco e Bahia e, Pirapora, em Minas Gerais (Mello, 2004). No Pólo Petrolina, PE/Juazeiro, BA, principal exportador de uvas do país, a cultivar Itália respondia por cerca de $63,2 \%$ do total da área plantada e era a principal uva exportada (Feitosa, 2002).

Porém, nos últimos anos, houve aumento considerável no plantio de cultivares apirenas, ou sem sementes, principalmente em regiões de clima tropical, em razão da demanda crescente do mercado externo e dos melhores rendimentos com a comercialização deste produto (Mello, 2004). Apesar de alcançar melhor preço de comercialização, a produção dessas cultivares no país vem apresentando diversos problemas referentes à adaptação. No Brasil, as principais cultivares plantadas e com grande aceitação no mercado mundial apresentam vigor elevado e baixa fertilidade de gemas, o que afeta significativamente a produtividade e a rentabilidade de seus cultivos (Leão et al., 2000; Grangeiro et al., 2002; Leão \& Silva, 2003). 
De acordo com Fregoni (1987), citado por Pires \& Pommer (2003), diversos fatores afetam a fertilidade de gemas das videiras. Entre eles estão os genéticos e os culturais, tais como variedade, porta-enxerto, idade da planta, vigor, dominância apical, hormônios promotores, hormônios inibidores, produção por planta e forma de condução; os climáticos como duração e intensidade da iluminação, comprimento de onda da luz, fotoperíodo, temperatura máxima, termoperíodo, pluviosidade e fatores edáficos e de manejo como alimentação hídrica, fertilidade do solo e técnicas culturais aplicadas ao solo.

Vários autores estudaram o cultivo de cultivares apirenas enxertadas em diferentes porta-enxertos. Freire et al. (1991) avaliaram o desempenho produtivo de plantas de 'Sultanina' sobre alguns porta-enxertos, que resultou em produtividades de $16,1 \mathrm{t} \mathrm{ha}^{-1}$ para plantas enxertadas em 'Harmony', 9,2 t ha ${ }^{-1}$ para 'Salt Creek', $8,3 \mathrm{t} \mathrm{ha}^{-1}$ para 'IAC-313 Tropical' e 6,4 $\mathrm{t} \mathrm{ha}^{-1}$ para 'Freedom', indicando maior produtividade de 'Sultanina' em plantas enxertadas em porta-enxertos menos vigorosos. Pommer et al. (2003) relataram que plantas da cultivar Superior Seedless, no Vale do São Francisco, enxertadas em 'IAC-766 Campinas', classificado como medianamente vigoroso, têm apresentado maiores fertilidades de gemas quando comparadas às plantas enxertadas em 'IAC-572 Jales' e 'IAC-313 Tropical', tidos como vigorosos.

No Brasil existem poucas informações sobre a definição dos porta-enxertos mais adequados para a produção de cultivares apirenas. $\mathrm{O}$ objetivo deste trabalho foi comparar o desempenho agronômico das cultivares Crimson Seedless e Superior Seedless, enxertadas nos porta-enxertos ' 1103 Paulsen' e 'IAC-572 Jales', de vigores distintos, cultivados no norte de Minas Gerais.

\section{Material e Métodos}

O experimento foi realizado na Fazenda Experimental da Empresa de Pesquisa Agropecuária de Minas Gerais (Epamig), em Mocambinho, Distrito de Jaíba, MG, localizado na região norte de Minas Gerais, entre os rios São Francisco e Verde Grande, a $15^{\circ} 0$ 'S e $43^{\circ} 40^{\prime} \mathrm{O}$, com topografia caracterizada por predominância de relevo plano e altitude de $449 \mathrm{~m}$. A temperatura média anual é de $24,2^{\circ} \mathrm{C}$ com média das mínimas de $14,8^{\circ} \mathrm{C}$ e média das máximas de $34,0^{\circ} \mathrm{C}$. A umidade relativa do ar varia entre 58 e 79\%. A insolação é de 2.892 horas por ano e a precipitação média anual é de cerca de $900 \mathrm{~mm}$, concentrando-se nos meses de outubro a março, com raras precipitações no período seco (Codevasf, 2004).

Os porta-enxertos foram plantados em julho de 2001 e enxertados em campo, pelo método da garfagem em fenda cheia, em julho de 2002. O sistema de condução adotado foi o de pérgula, com espaçamento de $3 \mathrm{~m}$ entre as plantas e de $3 \mathrm{~m}$ entre as linhas, e a formação das plantas com dois cordões principais do tipo "espinha de peixe". A irrigação foi feita por microaspersão. As plantas foram podadas duas vezes ao ano, deixandose em todas as safras ramos produtivos com 6 a 12 gemas e esporões com 2 a 3 gemas, dependendo da posição das gemas, vigor dos ramos e número de ramos produtivos por planta. Nas avaliações, foram consideradas cinco safras a partir do primeiro semestre do ano de 2003; duas com a colheita no final da primavera e início do verão, que corresponde ao período chuvoso, e três no final do outono e início do inverno, que compreende o período de baixa pluviosidade. As podas foram realizadas em 17/3/2003, 26/8/2003, 19/2/2004, 5/8/2004 e 5/3/2005.

As variáveis analisadas foram massa total de cachos, número de cachos, número de ramos e massa total de ramos, em cada planta. A contagem dos ramos ocorreu no início de ciclo, logo após a poda. Os cachos foram contados e pesados no momento da colheita. Com base em tais variáveis, calculou-se a massa média dos cachos de cada planta, dividindo-se a massa total de cachos pelo número de cachos por planta. Quanto ao cálculo da fertilidade de gemas, dividiu-se o número de cachos produzidos pelo número total de ramos em cada planta. Logo após a poda de cada ciclo, as folhas foram retiradas e os ramos de cada planta foram pesados, com exceção da primeira poda, quando as plantas ainda estavam em fase de formação da estrutura produtiva e não apresentavam esporões e varas de produção definidos. Na pesagem dos cachos e dos ramos podados, utilizou-se balança eletrônica com precisão de uma casa decimal. $\mathrm{O}$ experimento foi realizado em delineamento inteiramente casualizado, em esquema fatorial composto por dois fatores: porta-enxerto - 1103 Paulsen e IAC-572 Jales - e cultivar - Crimson Seedless e Superior Seedless -, com sete repetições.

A unidade experimental utilizada ocupou $729 \mathrm{~m}^{2}$, cujas parcelas foram separadas, por uma linha de plantas de bordadura no mesmo espaçamento das plantas úteis. Cada repetição foi composta por uma planta. As plantas avaliadas foram selecionadas e marcadas antes da primeira avaliação. Para isso foram escolhidas as plantas visualmente mais homogêneas quanto ao vigor e padrão 
de formação da estrutura produtiva. Os dados obtidos foram submetidos à análise de variância, utilizando-se o teste $\mathrm{F}$ e, na comparação das médias, foi utilizado o teste de Tukey, a 1 e $5 \%$ de probabilidade. Na comparação das produtividades, foi utilizado o teste de Scott-Knott, a $5 \%$ de probabilidade.

\section{Resultados e Discussão}

Não houve diferença significativa entre as massas de ramos podados de 'Crimson Seedless' e 'Superior Seedless' nas quatro safras analisadas (Tabela 1). Entre os porta-enxertos, o 'IAC-572 Jales' foi o que induziu à produção de maiores massas de ramos podados nas duas cultivares em todas as safras avaliadas, diferindo significativamente do '1103 Paulsen'. Na média das quatro safras, a massa dos ramos podados das plantas enxertadas em 'IAC-572 Jales' foi cerca de 30\% maior do que em '1103 Paulsen', o que caracteriza o maior vigor daquele porta-enxerto. Entretanto, esta diferença não foi muito grande nas cultivares copa. As plantas de 'Superior Seedless' apresentaram apenas 2,6\% mais massa em relação às de 'Crimson Seedless'. Leão (2002) relatou diferenças de vigor entre cinco cultivares sem sementes, em cinco ciclos de produção, em Petrolina, PE. As cultivares Sultanina e CG 39915 foram as de maior vigor, com 9,3 e 7,8 kg por planta, respectivamente, ao passo que a Vênus apresentou 1,5 kg por planta, Beauty Seedless, 2,4 kg por planta e Arizul, 2,9 kg por planta, e revelaram os menores valores da massa de ramos podados por planta. Pommer et al. (1999) também observaram diferença no vigor das videiras induzido pelos porta-enxertos. O porta-enxerto 'Kober 5BB' conferiu maior vigor às cultivares Crimson Seedless e Fantasy Seedless, em comparação com 'Ripária do Traviú' e 'IAC-766 Campinas', em Campinas, SP.

A fertilidade de gemas das cultivares Crimson Seedless e Superior Seedless, nas cinco safras deste experimento, está apresentada na Tabela 2. Quanto ao fator porta-enxerto, o '1103 Paulsen' induziu maior fertilidade de gemas para 'Crimson Seedless' e 'Superior Seedless', em todas as safras analisadas, diferindo significativamente do porta-enxerto 'IAC-572 Jales'. Ao se analisar as cultivares separadamente, 'Crimson Seedless' apresentou maior fertilidade de gemas em

Tabela 1. Massa de ramos podados das videiras 'Crimson Seedless' e 'Superior Seedless', enxertadas sobre '1103 Paulsen' e 'IAC-572 Jales', em Jaíba, MG, no período de 2003 a $2005^{(1)}$.

\begin{tabular}{lccccc}
\hline Cultivar/ & \multicolumn{5}{c}{ Massa de ramos podados por planta (kg) } \\
\cline { 2 - 6 } Porta-enxerto & $2^{\underline{0}}$ sem. 2003 & $1^{\underline{0}}$ sem. 2004 & $2^{\underline{0}}$ sem. 2004 & $1^{\underline{0}}$ sem. 2005 & Média \\
\hline Crimson Seedless & $8,7 \mathrm{a}$ & $4,1 \mathrm{a}$ & $9,3 \mathrm{a}$ & $7,8 \mathrm{a}$ & 7,5 \\
Superior Seedless & $9,1 \mathrm{a}$ & $3,8 \mathrm{a}$ & $10,9 \mathrm{a}$ & $7,1 \mathrm{a}$ & 7,7 \\
1103 Paulsen & $6,9 \mathrm{~b}$ & $3,3 \mathrm{~b}$ & $8,8 \mathrm{~b}$ & $6,3 \mathrm{~b}$ & 6,3 \\
IAC 572 Jales & $10,9 \mathrm{a}$ & $4,6 \mathrm{a}$ & $11,4 \mathrm{a}$ & $8,5 \mathrm{a}$ & 8,9 \\
\hline F (cultivar) & $0,147^{\mathrm{ns}}$ & $0,811^{\mathrm{ns}}$ & $2,905^{\mathrm{ns}}$ & $0,926^{\mathrm{ns}}$ & - \\
F (porta-enxerto) & $17,668^{* *}$ & $13,552^{* *}$ & $7,614^{*}$ & $8,439^{* *}$ & - \\
\hline CV $(\%)$ & 27,71 & 24,70 & 24,66 & 27,55 & - \\
\hline
\end{tabular}

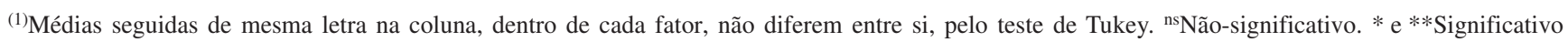
a 5 e $1 \%$ de probabilidade, respectivamente.

Tabela 2. Fertilidade de gemas das videiras 'Crimson Seedless' e 'Superior Seedless', enxertadas sobre '1103 Paulsen' e 'IAC-572 Jales', em Jaíba, MG, no período de 2003 a $2005^{(1)}$.

\begin{tabular}{|c|c|c|c|c|c|c|}
\hline \multirow{2}{*}{$\begin{array}{l}\text { Cultivar/ } \\
\text { Porta-enxerto }\end{array}$} & \multicolumn{6}{|c|}{ Fertilidade de gemas por planta ( $\mathrm{n}^{\circ}$ de cachos $/ \mathrm{n}^{\circ}$ de ramos) } \\
\hline & $1^{\circ}$ sem. 2003 & $2^{-}$sem. 2003 & $1^{\circ}$ sem. 2004 & $2^{-}$sem. 2004 & $1^{\circ}$ sem. 2005 & Média \\
\hline Crimson Seedless & $0,57 \mathrm{a}$ & $0,19 \mathrm{a}$ & $0,27 \mathrm{a}$ & $0,19 \mathrm{a}$ & $0,44 \mathrm{a}$ & 0,33 \\
\hline Superior Seedless & $0,18 \mathrm{~b}$ & $0,10 \mathrm{~b}$ & $0,30 \mathrm{a}$ & $0,12 b$ & $0,44 \mathrm{a}$ & 0,23 \\
\hline 1103 Paulsen & $0,53 \mathrm{a}$ & $0,23 \mathrm{a}$ & $0,33 \mathrm{a}$ & $0,20 \mathrm{a}$ & $0,70 \mathrm{a}$ & 0,40 \\
\hline IAC 572 Jales & $0,22 b$ & $0,06 \mathrm{~b}$ & $0,24 b$ & $0,11 \mathrm{~b}$ & $0,18 \mathrm{~b}$ & 0,16 \\
\hline F (cultivar) & $35,552 * *$ & $14,128 * *$ & $0,507^{\mathrm{ns}}$ & $9,527 * *$ & $0,002^{\mathrm{ns}}$ & - \\
\hline $\mathrm{F}$ (porta-enxerto) & $22,299 * *$ & $50,312 * *$ & $4,287^{*}$ & $25,686 * *$ & $99,162 * *$ & - \\
\hline $\mathrm{CV}(\%)$ & 46,58 & 45,46 & 40,90 & 32,52 & 31,67 & - \\
\hline
\end{tabular}

${ }^{(1)}$ Médias seguidas de mesma letra na coluna, dentro de cada fator, não diferem entre si, pelo teste de Tukey. ${ }^{\text {ns}}$ Não-significativo. $*$ e $* *$ Significativo a 5 e $1 \%$ de probabilidade, respectivamente. 
relação à 'Superior Seedless' na primeira, segunda e quarta safras. Na terceira e quinta safras, não houve diferença entre essas cultivares.

$\mathrm{Na}$ média das cinco safras, as plantas enxertadas em '1103 Paulsen' apresentaram fertilidade de gemas 60\% maior do que as enxertadas em 'IAC-572 Jales'. Entre as cultivares, a diferença foi de $30,3 \%$, com a maior fertilidade de gemas em Crimson Seedless. Na Itália, Antonacci \& Giovanni (2003) também observaram fertilidade de gemas superior para 'Crimson Seedless'. Naquele país, esta cultivar está classificada como de fertilidade real elevada, ao passo que 'Superior Seedless' é tida como de fertilidade real baixa.

Houve grande variação na fertilidade de gemas entre as safras, o que também foi observado por Leão \& Pereira (2001b), em Petrolina, PE, nas cultivares sem sementes: Vênus, Arizul, Beauty Seedless, Sultanina, Marroo Seedless e Canner Seedless.

A resposta das cultivares quanto ao número de cachos foi semelhante ao observado na fertilidade de gemas, em razão da utilização desta variável no cálculo da fertilidade de gemas (Tabela 3). As plantas enxertadas em '1103 Paulsen' foram as que produziram o maior número de cachos em quatro das cinco safras avaliadas. Não houve diferença entre os porta-enxertos apenas na safra do primeiro semestre de 2004. Com relação às cultivares, o número de cachos colhidos nas plantas de 'Crimson Seedless' foi maior do que nas de 'Superior Seedless' na primeira, segunda e quarta safras. $\mathrm{Na}$ terceira e na quinta safras, não houve diferença significativa entre as cultivares, apesar dos maiores valores observados em plantas de 'Crimson Seedless'.

Houve interação nas duas últimas safras. Na média das cinco safras, o porta-enxerto '1103 Paulsen' induziu ao aumento de 50,6\% no número de cachos, em relação ao 'IAC-572 Jales'. Entre as cultivares, as plantas de 'Crimson Seedless' produziram, em média, 32,3\% mais cachos do que 'Superior Seedless'. Nessa última, cultivada no Vale do São Francisco, Leão et al. (2004) observaram produção média de 36 cachos por planta, resultado maior do que o encontrado neste trabalho nos dois porta-enxertos, mas inferior ao número de cachos de 'Crimson Seedless' nos dois porta-enxertos. Entretanto, Pommer et al. (1997), em experimentação em Campinas, SP, não observaram grande diferença produtiva no híbrido sem sementes 'A1105' enxertado em 'IAC-766 Campinas' e 'Kober 5BB', apesar do vigor diferenciado entre esses porta-enxertos.

O porta-enxerto '1103 Paulsen' influenciou positivamente a produção, expressa em massa total de cachos por planta (Tabela 4). Somente na terceira safra, não houve diferença significativa quanto ao fator porta-enxerto. Nas outras quatro safras, o '1103 Paulsen' foi melhor que o 'IAC-572 Jales'. Quanto à cultivar, a produção das plantas de 'Crimson Seedless' foi maior do que a 'Superior Seedless', na primeira e na quinta safras, não havendo diferença significativa na segunda, terceira e quarta safras. Houve interação entre os fatores nas safras do primeiro semestre de 2003 e do segundo semestre de 2004. Na média das cinco safras avaliadas, a produção das plantas das duas cultivares enxertadas em ' 1103 Paulsen' foi cerca de três vezes maior do que quando enxertadas em 'IAC-572 Jales'. A 'Crimson Seedless' foi a mais produtiva das cultivares, com massa de cachos 1,5 vez maior do que 'Superior Seedless', independentemente do porta-enxerto utilizado.

Leão \& Pereira (2001a) haviam observado vigor excessivo e baixa produtividade das cultivares sem sementes Sultanina e Canner Seedless enxertadas em 'IAC-572 Jales', o que inviabiliza a exploração comercial dessas cultivares na região de Petrolina, PE. Entretanto,

Tabela 3. Número de cachos das videiras 'Crimson Seedless' e 'Superior Seedless', enxertadas sobre '1103 Paulsen' e 'IAC-572 Jales', em Jaíba, MG, no período de 2003 a 2005(1).

\begin{tabular}{|c|c|c|c|c|c|c|c|c|c|c|c|c|c|c|c|}
\hline \multirow[t]{3}{*}{ Cultivares } & \multicolumn{15}{|c|}{ Número de cachos por planta } \\
\hline & \multicolumn{3}{|c|}{$1^{\circ}$ semestre 2003} & \multicolumn{3}{|c|}{$2^{\circ}$ semestre 2003} & \multicolumn{3}{|c|}{$1^{\circ}$ semestre 2004} & \multicolumn{3}{|c|}{$2^{2}$ semestre 2004} & \multicolumn{3}{|c|}{$1^{\circ}$ semestre 2005} \\
\hline & $1103 \mathrm{P}$ & IAC572 & Média & $1103 \mathrm{P}$ & IAC572 & Média & $1103 \mathrm{P}$ & IAC572 & Média & $1103 \mathrm{P}$ & IAC572 & Média & $1103 \mathrm{P}$ & IAC572 & Média \\
\hline Crimson S. & 65,4 & 40,0 & $52,7 \mathrm{a}$ & 28,7 & 10,7 & $19,7 \mathrm{a}$ & 29,4 & 44,3 & $36,9 a$ & $27,0 \mathrm{Aa}$ & $11,3 \mathrm{Ba}$ & $19,2 \mathrm{a}$ & $75,6 \mathrm{Aa}$ & $35,0 \mathrm{Ba}$ & $55,3 a$ \\
\hline Superior S. & 24,3 & 1,3 & $12,8 \mathrm{~b}$ & 20,3 & 5,6 & $12,9 \mathrm{~b}$ & 39,3 & 29,6 & $34,5 \mathrm{a}$ & $16,3 \mathrm{Ab}$ & $13,3 \mathrm{Aa}$ & $14,8 \mathrm{~b}$ & $86,6 \mathrm{Aa}$ & $12,7 \mathrm{Bb}$ & $49,7 \mathrm{a}$ \\
\hline Média & $44,9 \mathrm{~A}$ & $20,7 \mathrm{~B}$ & & $24,5 \mathrm{~A}$ & $8,1 \mathrm{~B}$ & & $34,4 \mathrm{~A}$ & $37,0 \mathrm{~A}$ & & $21,7 \mathrm{~A}$ & $12,3 \mathrm{~B}$ & & $81,1 \mathrm{~A}$ & $23,9 \mathrm{~B}$ & \\
\hline $\mathrm{F}$ (cultivar) & & $48,570 * *$ & & & $6,703 *$ & & & $0,133^{\mathrm{ns}}$ & & & $4,920 *$ & & & $0,870^{\mathrm{ns}}$ & \\
\hline $\begin{array}{l}\mathrm{F} \text { (porta- } \\
\text { enxerto) }\end{array}$ & & $17,862 * *$ & & & $38,951 * *$ & & & $0,149^{\mathrm{ns}}$ & & & $22,690 *$ & & & $89,409 * *$ & \\
\hline $\mathrm{CV}(\%)$ & & 46,28 & & & 42,49 & & & 49,45 & & & 30,64 & & & 30,51 & \\
\hline
\end{tabular}

(1)Médias seguidas de mesma letra, maiúscula na linha e minúscula na coluna, dentro de cada fator, não diferem entre si, pelo teste de Tukey.

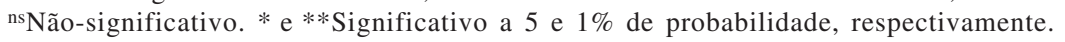


os autores compararam estas cultivares com outras quatro cultivares sem sementes e não avaliaram a influência sobre o vigor e produção de cachos que outros porta-enxertos poderiam apresentar nas mesmas cultivares em condições de clima tropical.

Além de características produtivas, é importante que o porta-enxerto influencie também a qualidade da produção. Luvisi et al. (2001) destacaram que, na Califórnia, as cultivares Crimson Seedless, Flame Seedless, Sultanina e Redglobe produziram as maiores quantidades de uvas de primeira qualidade quando enxertadas sobre '1103 Paulsen', em comparação com outros nove porta-enxertos. Os autores recomendaram a utilização deste porta-enxerto para o cultivo de uvas de mesa naquela região, com 'Freedom' e 'Ramsey'. Venegas \& Martinez-Peniche (2001), ao estudar o comportamento da videira 'Ruby Seedless' enxertada sobre oito porta-enxertos, na região árida do Centro-Norte do México, relataram diferentes massa e comprimento dos cachos, massa de bagas, acidez, concentração de açúcar, turgidez, degrana ou esbagoamento e escurecimento da ráquis. Esses autores também associaram os menores valores de massa de cachos aos porta-enxertos de maior vigor, atribuindo a estes porta-enxertos o menor pegamento das bagas.

A produtividade das combinações entre cultivares e porta-enxertos nas safras em que foi realizado o experimento foi estimada, combinando-se a produção por planta e a densidade de plantas empregada (Tabela 5).

Houve tendência de maior produtividade na primeira safra de cada ano, quando a poda foi realizada no final do período chuvoso e a colheita nos meses de junho e julho. A diferença de produtividade entre os primeiros e segundos semestres foi de 8,6 $\mathrm{t} \mathrm{ha}^{-1}$ para 'Crimson
Seedless'/'1103 Paulsen', 7,1 t ha ${ }^{-1}$ para 'Crimson Seedless'/'IAC-572 Jales', 5,8 t ha-1 para 'Superior Seedless'/'1103 Paulsen' e de 1,2 t ha-1 para 'Superior Seedless'/'IAC-572 Jales'. A melhor média de produtividade entre todas as safras foi observada em 'Crimson Seedless' enxertada em '1103 Paulsen', seguida por 'Superior Seedless' em '1103 Paulsen', 'Crimson Seedless' em 'IAC-572 Jales' e 'Superior Seedless' em 'IAC-572 Jales'. Entretanto, considerando-se somente as médias de produtividade dos primeiros semestres, observa-se aumento considerável nesses valores.

Grangeiro et al. (2002) obtiveram produtividades de 7,41 e 3,20 t ha-1 de 'Superior Seedless' enxertada sobre 'IAC-572 Jales', no segundo semestre de 1999 e primeiro semestre de 2000, respectivamente. Essas produtividades foram superiores às médias encontradas neste trabalho quanto à mesma combinação de copa/porta-enxerto, mas inferiores às produtividades observadas para 'Crimson Seedless'/'1103 Paulsen' e 'Superior Seedless'/'1103 Paulsen'. Em outro experimento, com apenas uma produção anual e duas podas, Leão et al. (2004) obtiveram produtividades médias de $11,78 \mathrm{e}$ 6,3 $\mathrm{t} \mathrm{ha}^{-1} \mathrm{ano}^{-1}$ nas safras de julho de 2001 e 2002, em avaliação dos efeitos do anelamento e aplicação de reguladores de crescimento na videira 'Superior Seedless', enxertada sobre 'IAC-572 Jales', em Petrolina, PE.

Ao se considerar duas safras anuais, as médias de produtividade observadas para 'Crimson Seedless'/ '1103 Paulsen' podem ser comparadas às médias de produtividade encontradas na videira 'Itália' e suas mutações nas principais regiões produtoras do país (Leão, 2001; Pommer et al., 2003) (Tabela 5). A combinação 'Superior Seedless'/'1103 Paulsen' apresentou maiores produtividades do que as encontradas

Tabela 4. Massa total de cachos das videiras 'Crimson Seedless' e 'Superior Seedless', enxertadas sobre '1103 Paulsen' e 'IAC-572 Jales' em Jaíba, MG, no período de 2003 a $2005^{(1)}$.

\begin{tabular}{|c|c|c|c|c|c|c|c|c|c|c|c|c|c|c|c|}
\hline \multirow[t]{3}{*}{ Cultivares } & \multicolumn{15}{|c|}{ Massa total de cachos por planta $(\mathrm{kg})$} \\
\hline & \multicolumn{3}{|c|}{$1^{0}$ semestre 2003} & \multicolumn{3}{|c|}{$2^{\circ}$ semestre 2003} & \multicolumn{3}{|c|}{$1^{\circ}$ semestre 2004} & \multicolumn{3}{|c|}{$2^{\circ}$ semestre 2004} & \multicolumn{3}{|c|}{$1^{\circ}$ semestre 2005} \\
\hline & $1103 \mathrm{P}$ & IAC572 & Média & $1103 \mathrm{P}$ & IAC572 & Média & $1103 \mathrm{P}$ & IAC572 & Média & $1103 \mathrm{P}$ & IAC572 & Média & $1103 \mathrm{P}$ & IAC572 & Média \\
\hline Crimson S. & $22,4 \mathrm{Aa}$ & $7,3 \mathrm{Ba}$ & $14,9 \mathrm{a}$ & 8,0 & 2,3 & $3,8 \mathrm{a}$ & 6,6 & 8,9 & $7,8 \mathrm{a}$ & $11,5 \mathrm{Aa}$ & $2,5 \mathrm{Ba}$ & $7,0 \mathrm{a}$ & 23,3 & 10,3 & $16,8 \mathrm{a}$ \\
\hline Superior S. & $7,3 \mathrm{Ab}$ & $0,2 \mathrm{Bb}$ & $3,8 \mathrm{~b}$ & 6,5 & 1,2 & $5,1 \mathrm{a}$ & 8,7 & 6,0 & $7,4 \mathrm{a}$ & $7,4 \mathrm{Ab}$ & $3,3 \mathrm{Ba}$ & $5,4 \mathrm{a}$ & 20,5 & 3,8 & $12,2 \mathrm{~b}$ \\
\hline Média & $14,9 \mathrm{~A}$ & $3,8 \mathrm{~B}$ & & $7,2 \mathrm{~A}$ & $1,8 \mathrm{~B}$ & & $7,7 \mathrm{~A}$ & $7,5 \mathrm{~A}$ & & $9,5 \mathrm{~A}$ & $2,9 \mathrm{~B}$ & & $21,9 \mathrm{~A}$ & $7,1 \mathrm{~B}$ & \\
\hline F (cultivar) & & $35,551^{* *}$ & & & $2,369^{\mathrm{n}}$ & & & $0,051^{\mathrm{n}}$ & & & $2,871^{\mathrm{ns}}$ & & & 8,804 & \\
\hline $\mathrm{F}($ porta-enx & (erto) & $35,097 * *$ & & & $41,748^{\circ}$ & & & $0,021^{\mathrm{n}}$ & & & $48,530 * *$ & & & 88,325 & \\
\hline $\mathrm{F}(\mathrm{PxC})$ & & $4,537^{*}$ & & & $0,041^{\mathrm{n}}$ & & & $2,404^{\mathrm{n}}$ & & & $6,751^{*}$ & & & $1,411^{1}$ & \\
\hline CV $(\%)$ & & 53,23 & & & 49,74 & & & 56,74 & & & 40,64 & & & 28,88 & \\
\hline
\end{tabular}

${ }^{(1)}$ Médias seguidas de mesma letra, maiúscula na linha e minúscula na coluna, dentro de cada fator, não diferem entre si, pelo teste de Tukey. nsNão-significativo. * e**Significativo a 5 e $1 \%$ de probabilidade, respectivamente. 
Tabela 5. Produtividade estimada das videiras 'Crimson Seedless' e 'Superior Seedless', enxertadas sobre '1103 Paulsen' e 'IAC-572 Jales', em Jaíba, MG, no período de 2003 a $2005^{(1)}$.

\begin{tabular}{|c|c|c|c|c|}
\hline \multirow[t]{2}{*}{ Época de poda } & \multicolumn{4}{|c|}{ Cultivar/porta-enxerto $\left(\mathrm{t} \mathrm{ha}^{-1}\right)$} \\
\hline & Crimson S./1103P & Crimson S./572 & Superior S./1103P & Superior S./572 \\
\hline $1^{\circ}$ semestre 2003 & $24,9 a$ & $8,1 \mathrm{a}$ & $8,1 \mathrm{~b}$ & $0,2 \mathrm{c}$ \\
\hline $2^{\circ}$ semestre 2003 & $8,9 \mathrm{~b}$ & $2,6 \mathrm{~b}$ & $7,2 \mathrm{~b}$ & $1,3 \mathrm{c}$ \\
\hline $1^{\circ}$ semestre 2004 & $7,3 b$ & $9,9 \mathrm{a}$ & $9,7 \mathrm{~b}$ & $6,7 \mathrm{a}$ \\
\hline $2^{2}$ semestre 2004 & $12,8 \mathrm{~b}$ & $2,8 \mathrm{~b}$ & $8,2 \mathrm{~b}$ & $3,7 b$ \\
\hline $1^{\circ}$ semestre 2005 & $25,9 \mathrm{a}$ & $11,4 \mathrm{a}$ & $22,8 \mathrm{a}$ & $4,2 b$ \\
\hline $\mathrm{F}$ & $14,940 * *$ & $19,198 * *$ & $13,413 * *$ & $8,266^{* *}$ \\
\hline $\mathrm{CV}(\%)$ & 38,05 & 35,63 & 42,13 & 72,68 \\
\hline Total (5 safras) & 79,8 & 34,8 & 56,0 & 16,1 \\
\hline Média $1^{\circ}$ semestre & 19,4 & 9,8 & 13,5 & 3,7 \\
\hline Média $2^{\circ}$ semestre & 10,8 & 2,7 & 7,7 & 2,5 \\
\hline Média por safra & 16,0 & 7,0 & 11,2 & 3,2 \\
\hline Média anual & 31,9 & 13,9 & 22,4 & 6,4 \\
\hline
\end{tabular}

${ }^{(1)}$ Médias seguidas de mesma letra na coluna não diferem entre si pelo teste de Scott-Knott, a $1 \%$ de probabilidade. **Significativo a $1 \%$ de probabilidade.

para a mesma variedade por Leão et al. (2000) na região de Jaboticabal, SP, com 6,6 t ha- ano $^{-1}$; por Grangeiro et al. (2002), em Petrolina, PE, com $10,6 \mathrm{t} \mathrm{ha}^{-1}$ ano $^{-1}$ e por Leão et al. (2004), também em Petrolina, PE, com 18,1 t ha' ano $^{-1}$. Leão (2002) destacou as cultivares Vênus e Marroo Seedless como de grande potencial de cultivo na região do Vale do São Francisco, com produtividades de 24 e $20 \mathrm{t} \mathrm{ha}^{-1}$ ano $^{-1}$, abaixo da produtividade obtida para a 'Crimson Seedless'/'1103 Paulsen' e semelhante à produtividade de 'Superior Seedless'/' 1103 Paulsen' neste trabalho.

\section{Conclusões}

1. O porta-enxerto 'IAC-572 Jales' induz às plantas de 'Crimson Seedless' e 'Superior Seedless' maior vigor e menor fertilidade de gemas.

2. O porta-enxerto '1103 Paulsen' induz a maior produtividade em 'Crimson Seedless' e 'Superior Seedless'.

\section{Referências}

ANTONACCI, D.; GIOVANNI, R. di. Nuove varietà di uva da tavola in Abruzzo. Rivista di Frutticoltura e di Ortofloricoltura, v.65, p.16-25, 2003.

CODEVASF. Informações edafoclimáticas. Disponível em: <http:/ /www.codevasf.com.br>. Acesso em: 24 abr. 2004.

FEITOSA, C.A.M. Efeitos do CPPU e $\mathrm{GA}_{3}$ no cultivo de uva Itália na região do Submédio São Francisco, Nordeste do Brasil. Revista Brasileira de Fruticultura, v.24, p.348-353, 2002.
FREIRE, L.C.L.; ALBUQUERQUE, J.A.S. de; ALBUQUERQUE, T.C.S. de. Comportamento da cultivar 'Thompson Seedless' sobre diferentes porta-enxertos na região do Submédio São Francisco. Revista Brasileira de Fruticultura, v.13, p.129-133, 1991.

GRANGEIRO, L.C.; LEÃO, P.C. de S.; SOARES, J.M. Caracterização fenológica e produtiva da variedade de uva Superior Seedless cultivada no Vale do São Francisco. Revista Brasileira de Fruticultura, v.24, p.552-554, 2002.

LEÃO, P.C. de S. Comportamento de cultivares de uva sem sementes no Submédio São Francisco. Revista Brasileira de Fruticultura, v.24, p.734-737, 2002.

LEÃO, P.C. de S. Principais cultivares de uvas finas de mesa. In: LEÃO, P.C. de S. Uva de mesa: produção, aspectos técnicos. Brasília: Embrapa Informação Tecnológica, 2001. p.26-33.

LEÃO, P.C. de S.; NACHTIGAL, J.C.; PEREIRA, F.M.; KOBA, V.Y. Comportamento fenológico e produtivo das variedades de uva "Ribol" e "Superior Seedless" na região de Jaboticabal, SP. Revista Brasileira de Fruticultura, v.22, p.300-302, 2000.

LEÃO, P.C. de S.; PEREIRA, F.M. Avaliação de seis variedades de uvas sem sementes no Submédio São Francisco. Pesquisa Agropecuária Brasileira, v.36, p.607-613, 2001a.

LEÃO, P.C. de S.; PEREIRA, F.M. Estudo da brotação e da fertilidade de gemas de cultivares de uvas sem sementes nas condições tropicais do Vale do Submédio São Francisco. Revista Brasileira de Fruticultura, v.23, p.30-34, 2001b.

LEÃO, P.C. de S.; SILVA, E.E.G. da. Brotação e fertilidade de gemas em uvas sem sementes no Vale do São Francisco. Revista Brasileira de Fruticultura, v.25, p.375-378, 2003.

LEÃO, P.C. de S.; SILVA, D.J.; SILVA, E.E.G. da. Anelamento e reguladores de crescimento: efeitos sobre as medidas biométricas e qualidade de cachos da videira "Superior Seedless". Revista Brasileira de Fruticultura, v.26, p.385-388, 2004.

LUVISI, D.A.; HASHIM, J.M.; SCHRADER, P.L. I portinnesti per l'uva da tavola in California. Rivista di Frutticoltura e di Ortofloricoltura, v.63, p.29-43, 2001. 
MELLO, L.M.R. de. Produção e comercialização de uvas. In: NACHTIGAL, J.C.; CAMARGO, U.A.; CONCEICAO, M.A.F. (Ed.). Uvas sem sementes: cultivares BRS Morena, BRS Clara e BRS Linda. Bento Gonçalves: Embrapa Uva e Vinho, 2004. p.11-14. (Embrapa Uva e Vinho. Sistemas de produção, 1).

PIRES, E.J.P.; POMMER, C.V. Fisiologia da videira. In: POMMER, C.V. Uva: tecnologia de produção, pós-colheita, mercado. Porto Alegre: Cinco Continentes, 2003. p.250-294.

POMMER, C.V.; MARTINS, F.P.; PASSOS, I.R. da S.; PIRES, E.J.P.; TERRA, M.M. Avaliação do clone híbrido A1105 de uvas brancas sem sementes sobre dois porta-enxertos. Bragantia, v.56, p.163-168, 1997.
POMMER, C.V.; TERRA, M.M.; PIRES, E.J.P. Cultivares, melhoramento e fisiologia. In: POMMER, C.V. Uva: tecnologia de produção, pós-colheita, mercado. Porto Alegre: Cinco Continentes, 2003. p.109-152.

POMMER, C.V.; TERRA, M.M.; PIRES, E.J.P.; PASSOS, I.R. da S.; MARTINS, F.P. Introdução dos cultivares de uva de mesa 'Fantasia' e 'Ruiva' no Brasil. Scientia Agricola, v.56, p.247-253, 1999.

VENEGAS, M.C.; MARTÍNEZ-PENICHE, R. Rootstock influences quality of 'Ruby Seedless' table grape (Vitis vinifera L.) in Central-Northern Mexico. Acta Horticulturae, v.565, p.125-130, 2001. 